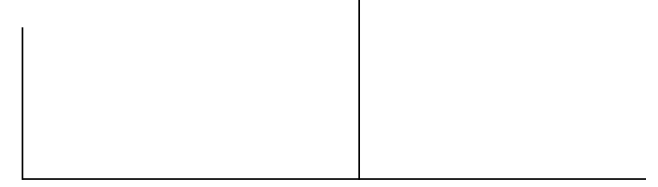

Rev. Latinoam. Psicop. Fund. V, 4, 130-141

\title{
Da loucura circular, ou forma de doença mental caracterizada pela alternância regular da mania e da melancolia ${ }^{1,2}$
}

\author{
Jean-Pierre Falret (1854)
}

\begin{abstract}
Nós já indicamos anteriormente o que entendemos pela expressão loucura circular. Agora nos propomos a dar uma descrição mais extensa dessa nova forma de doença mental. Mas, antes de abordar essa mesma descrição, é importante assinalar alguns fatos de remissão e de intermitência nas doenças mentais, que poderiam ser confundidos com essa forma, se não começássemos a diferenciá-los. É o único meio de tornar bem compreensível o que nós entendemos por loucura circular.
\end{abstract}

1. A tradução é de Maria Vera Pompeo de Camargo Pacheco e a revisão técnica é do Prof. Dr. Mário Eduardo Costa Pereira, ambos do Laboratório de Psicopatologia Fundamental da Unicamp.

2. Há muito tempo nós descrevíamos essa nova forma de doença mental, em nossos cursos clínicos no asilo da Salpetrière quando, em 31 de janeiro de 1854, o sr. Baillanger veio fazer uma conferência sobre o mesmo tema na Academia Imperial de Medicina. Na sessão seguinte (7 de fevereiro), para reivindicar a prioridade dessa idéia, nós lemos pessoalmente o presente trabalho na Academia. A partir dessa ocasião, sr. Baillanger discutiu, no Bulletin de l'Académie e nos Annales médico-psychologiques, nossa maneira de ver e explicar o que ele compreendia sob o nome de loucura de dupla forma, e em que ela diferia, segundo ele, do que havíamos chamado de loucura circular. Não é aqui o lugar de nos deixarmos levar por uma controvérsia a esse respeito. Nós nos limitaremos então a reproduzir nosso trabalho, tal como o lemos na Academia e tal como foi publicado no Bulletin (t. XIX, p. 382 e seg., sessão de 14 de fevereiro de 1854). 


\section{CLÁSSICO S DA \\ PSICOPATOLOGIA \\ ano $V$, n. 4, dez/ 2002}

Em todas as alienações mentais, existem remissões mais ou menos notáveis, e paroxismos mais ou menos intensos; nada é mais raro do que um curso contínuo da doença com a mesma intensidade e as mesmas características. Isso é um fato geralmente conhecido e que se observa tanto na medicina comum como na medicina mental. No entanto, segundo o que pensamos, não se insistiu suficientemente sobre a freqüência e a intensidade dessas remissões e desses paroxismos no curso das doenças mentais, e diversos erros capitais foram conseqüência dessa lacuna na observação. Na alienação geral, por exemplo, é uma das causas pelas quais tantos doentes, tão diferentes uns dos outros, são classificados indistintamente sob o nome genérico de maníacos. É também uma das causas pelas quais existe e perpetua-se no estudo das alienações parciais, a doutrina da unidade do delírio, da monomania. Essa doutrina é tão errônea do ponto de vista da ciência, e tão funesta ao tratamento e à medicina legal dos alienados porque assimila a loucura à paixão extrema, e não permite estabelecerse nenhuma linha de demarcação entre elas.

O fato da intermitência nas doenças mentais é igualmente muito conhecido; todo mundo admite, por exemplo, a mania intermitente. Mas como existem coisas a serem explicitadas a respeito da regularidade ou da irregularidade da intermitência, assim como sobre as características que podem fazer com que ela seja pressentida! Que sinais reconhecer, desde o primeiro acesso, que uma loucura será intermitente? Como distinguir o retorno de um acesso de loucura intermitente de uma recaída comum, provocada pela ação de novas causas, como em qualquer outra doença?

Entretanto em nossa opinião, vários elementos para a solução dessas questões já são adquiridos pela ciência. Assim, as loucuras que deverão ser intermitentes em geral têm uma invasão súbita, um desenvolvimento de continuidade mais uniforme, menos paroxística durante o acesso; e a cura enfim ocorre mais rapidamente, algumas vezes, mesmo de repente, e não por nuanças insensíveis. É justo dizer entretanto, que habitualmente observa-se alguns sinais de diminuição; mas no espaço de oito a quinze dias, o doente passa do summum da doença à cura do acesso. Além do que, nas loucuras intermitentes, o acesso posterior parece, em todos os pontos, com os acessos precedentes, pelos sintomas físicos, intelectuais e morais, mesmo pelas idéias delirantes expressas, assim como por sua evolução. O doente geralmente passa, quase de maneira fatal, por todas as fases dos acessos anteriores.

A duração de cada acesso pode ser, e freqüentemente é, mais longa à medida que o doente avança na vida; mas é um erro acreditar que a loucura intermitente acaba sempre por tornar-se contínua. Esse é, ao contrário, um fato muito excepcional. A verdade é que se os acessos anteriores foram bem 
observados, pode-se com freqüência assinalar previamente a época da cura do acesso em curso. Esse conhecimento é de grande interesse do ponto de vista do prognóstico, e da tripla relação do doente, de sua família e da sociedade. Mas, se cada ataque de loucura intermitente é certamente mais curável que muitas outras doenças mentais, por outro lado essa espécie de loucura é incurável em sua essência. Deve-se esperar vê-la reproduzir-se no curso da vida, ainda que, no entanto, seja possível, por meio de conselhos esclarecidos, retardar o desenvolvimento dos acessos e até mesmo fazer abortar alguns deles. Aliás, nós devemos assinalar que se existem loucuras intermitentes que se manifestam com regularidade em épocas determinadas, não há, no entanto, em geral, nada de regular quanto ao tempo de sua manifestação, e não se pode dizer que a intermitência nas doenças mentais seja periodicidade. Assim como sensatas precauções a retardam, impedem seu desenvolvimento, também as causas excitantes podem precipitar sua explosão.

Independentemente desses fatos da intermitência de longos intervalos, existem fatos de intermitência de curtos intervalos, ou seja, de oito dias, de quinze dias, de três semanas, ou de um mês, aos quais não se deu suficiente importância, mas que no entanto são bastante dignos de uma observação especial, sobretudo do ponto de vista do prognóstico. Os fatos dessa ordem sem dúvida constituirão um dia uma variedade particular de doença mental intermitente. Há muito tempo elas são objeto de nossa atenção. Não pode fazer parte de nosso plano dar aqui detalhes a esse respeito, mas devemos dizer que nesses casos, os acessos são curtos e separados uns dos outros por um estado lúcido completo e em geral de mesma duração que o próprio acesso de alienação mental. Observa-se essa forma de intermitência principalmente na alienação geral com excitação. Raramente essas loucuras intermitentes de curtos intervalos são passíveis de cura; são inclusive menos curáveis que as loucuras intermitentes de longos intervalos. O que algumas vezes consegue-se nesses casos é um intervalo de bem-estar mais prolongado entre os acessos.

Compreende-se o quanto a observação das loucuras intermitentes de curtos acessos, separados por curto intervalo lúcido, pode ser útil para o prognóstico pelo fato de decidir questões relativas à internação ou à saída dos alienados dos estabelecimentos que lhes são consagrados e ainda pelo fato de resolver certas questões de medicina legal, como, por exemplo, julgar se um doente, durante um acesso, cometeu um ato, que o juiz é solicitado a apreciar, no período de um intervalo de lucidez.

Ao lado dessa ordem de fatos encontram-se os da loucura remitente, quer dizer, de loucura contínua com exacerbações e remissões tão fracionadas que é preciso observá-la com muita exatidão para diferenciá-la das loucuras 


\section{CLÁSSICO S DA \\ PSICOPATOLOGIA \\ ano $V$, n. 4, dez/ 2002}

intermitentes de curtos intervalos. Por outro lado, essas remissões distinguemse das remissões que ocorrem em todas as loucuras, onde são mais longas, muito mais marcadas e, sobretudo, mais freqüentes e mais aproximadas.

Observando-se esses doentes, percebe-se claramente que a perturbação da inteligência e dos sentimentos ainda existe num certo grau; que eles apresentam muitas lacunas em sua maneira de falar e de agir em relação às pessoas ao seu redor e que, apesar de sua melhora tão notável, o mais comum é que não reconheçam que estão alienados. A loucura remitente merece ainda mais ser diferenciada das loucuras intermitentes de curtos intervalos, à medida que seu prognóstico é relativamente menos grave. Os alienados dessa categoria são susceptíveis de cura, e as chances em geral são tanto maiores quanto mais longa e mais nítida for cada remitência, desde que em todas as vezes a remitência não seja uma suspensão completa da doença. Existe, sem dúvida, um grande número desses doentes que não se curam, mas as probabilidades de cura são mais numerosas que nas formas francamente intermitentes.

As distinções que acabamos de estabelecer sumariamente nos pareceram indispensáveis para permitir, por comparação, uma compreensão clara do que nós entendemos por loucura circular.

Efetivamente, não queremos designar com essa palavra nenhuma das alienações mentais de que acabamos de falar. Acrescentaremos que, na mania, observa-se algumas vezes estados melancólicos mais ou menos pronunciados e mais ou menos duráveis; que certo número de maníacos apresentam, antes da explosão de agitação, um estado melancólico com uma duração mais ou menos longa, ou, então, antes de curarem-se completamente, oferecem um período de prostração, que é provavelmente o efeito de descontroles nervosos excessivos; que, por outro lado, às vezes constatamos na alienação parcial, paroxismos maníacos que é mesmo uma melancolia ansiosa, notável por uma necessidade incessante de movimento e uma agitação interior que faz o desespero do doente e não permitem-lhes fixar-se em nada, estado que pode chegar, e chega às vezes, até à agitação maníaca. Acrescentaremos finalmente que a transformação da mania em melancolia, ou reciprocamente, acontece em alguns casos de maneira acidental, como todos os autores sempre o notaram. Mas, para constituir a loucura circular, a depressão e a excitação devem suceder-se durante um longo tempo (e sucedem-se mais freqüentemente durante toda a vida), de uma maneira quase regular, sempre numa mesma ordem e com um intervalo de razão geralmente bastante curto em relação à duração dos acessos.

A loucura circular é então caracterizada pela evolução sucessiva e regular de estado maníaco e de estado melancólico e de um intervalo lúcido mais ou menos prolongado. Varia de intensidade e de duração no conjunto e em cada um 
de seus períodos, seja nos diversos doentes, seja nos diversos acessos de um mesmo doente.

Ora o círculo é descrito em três semanas ou um mês, ora somente se completa após vários meses ou vários anos. Além disso, esse caráter de duração não muda nada na natureza da doença, quer a evolução seja lenta ou rápida; ela permanece a mesma em suas características gerais, assim como em seus principais detalhes. Pensamos também que é uma forma verdadeira de doença mental porque consiste num conjunto de sintomas físicos, intelectuais e morais, sempre idênticos entre si nos diversos períodos e sucedendo-se numa ordem determinada, de tal sorte que, ao encontrarmos alguns deles, podemos anunciar previamente a evolução posterior da doença.

A mais justo título que a mania e a melancolia, ela é mesmo uma forma natural, pois não é baseada numa única característica principal, a quantidade de delírios, a tristeza ou a agitação, mas sim na reunião de três estados particulares, sucedendo-se numa ordem determinada possível de ser prevista, e não sendo susceptível de transformação. Uma característica geral da loucura circular é a semelhança, no mesmo doente, de cada um dos períodos de cada acesso. Ela ocorre não somente nos sintomas principais, mas na maioria dos detalhes; não somente no fato da excitação ou da depressão, mas nas idéias e nos sentimentos expressos pelos doentes, assim como nos sintomas físicos. Essa semelhança algumas vezes chega até à reprodução das mesmas manifestações na mesma época de cada período.

Fica-se verdadeiramente estupefato de ver a monotonia e a uniformidade da existência física e moral desses doentes acometidos de loucura circular, e tais observações são bem próprias para fazer sentir o quanto se está enganado, o quanto é pouco científico acreditar que tudo é individual e acidental nas manifestações delirantes dos alienados. Quanto mais profundamente se observa esses doentes, mais ficamos convencidos que as variedades tão numerosas das doenças mentais, fundadas sobre o objeto do delírio, sobre as idéias dominantes, e que na primeira abordagem parecem não ter outros limites além da imaginação do homem, são, ao contrário, redutíveis a um pequeno número de formas especiais que a observação posterior descobrirá. Nós já temos, em minha opinião, um espécimen dessas formas naturais na loucura paralítica, tão precisamente diferenciada das outras espécies de doença mental, por M. Parchappe, e na loucura circular, que nós mesmos tentamos estabelecer nesse momento.

Para facilitar a descrição, chamaremos de acesso da loucura circular a reunião de três períodos cuja sucessão forma o círculo completo. Será suficiente descrevermos um desses círculos para darmos uma idéia exata de todos os outros, pois eles se parecem entre si no mesmo doente, como acabamos de dizer. 


\section{CLÁSSICO S DA \\ PSICOPATOLOGIA \\ ano $V$, n. 4, dez/ 2002}

Comecemos pelo estado maníaco. Em geral, esse estado é caracterizado por uma simples exaltação da inteligência e dos sentimentos que, de início, é apenas notado como um dos momentos felizes onde o espírito desenvolve-se com atividade, ou tudo parece fácil e onde a natureza apresenta-se com o aspecto mais risonho. O doente oferece então apenas maior atividade de todas as faculdades e pareceria modificado para melhor aos olhos de espectadores espantados, se não se visse já despontar algumas ligeiras alterações de sentimentos, e se os atos não começassem a parecer estranhos e mesmo desordenados. Progressivamente e em muito pouco tempo, o mal aumenta; a exuberância das idéias torna-se prodigiosa; os sentimentos exaltam-se; testemunhos de ternura são dados às pessoas anteriormente indiferentes, e manifestações raivosas explodem contra as pessoas outrora as mais queridas. Os movimentos são rápidos e incessantes. É nesse período que os doentes deixados livres se deslocam, perdem todos os seus móveis, mudam de apartamento, desarrumam seus jardins, são travessos, maldosos e fazem todas as espécies de truques, fazem projetos, os executam quase instantaneamente, compõem, escrevem em prosa e em verso, e essa prodigiosa atividade, que transborda por todas as saídas, é também durante a noite o que é durante o dia. O doente experimenta o sentimento de uma saúde física perfeita. Efetivamente, com freqüência, os estados anteriormente doentios suspendem-se durante esse período de excitação. O apetite aumenta; todas as funções orgânicas parecem ter uma atividade maior e, apesar da falta de sono, o doente suporta alegremente e sem fadiga alguma todos os movimentos incessantes e todos os excessos aos quais ele se entrega. A face fica colorida, os olhos brilhantes, animados; os traços do rosto são de grande mobilidade e todos os sentidos adquirem uma extrema acuidade.

A excitação que acabamos de descrever, habitualmente prolonga-se, mais ou menos no mesmo grau, durante toda a duração desse período, sem apresentar essa desordem extrema e geral das idéias e dos sentimentos que constitui a mania comum. Entretanto, há um certo número de casos nos quais o período de excitação consiste num verdadeiro acesso de mania, muitas vezes até com ilusões e alucinações muito intensas e muito pronunciadas.

É mais freqüente ainda constatar nos doentes que habitualmente têm uma simples exaltação maníaca, paroxismos durante os quais o delírio é completamente maníaco e apresenta inclusive alguns sintomas de debilidade intelectual, sobretudo quando a doença já é antiga. Devemos observar no entanto que, nesses mesmos casos, os doentes geralmente apresentam apenas exaltação e uma superexcitação de todas as faculdades, e somente por exceção e temporariamente, o delírio maníaco. 
Vemos essa excitação diminuir progressivamente após um tempo maior ou menor, segundo os doentes, como havia aumentado no começo do período maníaco. No momento em que cessa a excitação, produz-se um estado bastante difícil de ser caracterizado: participa da excitação, muito diminuída, que acaba e da depressão que começa. Estaria aí um verdadeiro intervalo lúcido? Nós respondemos negativamente, levando em consideração a generalidade dos fatos. Existem no entanto alguns casos excepcionais, e reconhecemos que se não se realiza um exame aprofundado, pode-se acreditar que esses fatos sejam mais numerosos do que realmente são, ou mesmo acreditar numa cura verdadeira. Efetivamente, os doentes nessa época apresentam um tal contraste com o estado que acaba de terminar que podem parecer sensatos. Podem exercer um domínio suficiente sobre si mesmos para não deixar aparecer o distúrbio da inteligência, que, aliás, pode acontecer apenas momentaneamente. Eles habitualmente dissimulam algumas idéias delirantes que lhes restam ainda do período de exaltação, ou algumas outras que começam a despontar e indicam a iminência do período de depressão. Enfim, para avaliar seu verdadeiro estado, é conveniente constatar de preferência as omissões do que as manifestações. Percebe-se então que os doentes não falam e não agem, como o fariam em seu lugar, pessoas que estivessem no estado normal. Os fatos negativos que se reúne por meio de uma tal observação são preciosos para que se julgue que eles não estão num verdadeiro intervalo lúcido. Porém, mesmo tomando essas precauções na observação, excepcionalmente constata-se alguns casos onde a razão parece ter retornado ao que era anteriormente. Mas a duração desse estado é curta, mesmo nas loucuras circulares de longa duração; é sempre menos prolongada que a do estado lúcido que se manifesta em seguida à depressão. É um estado no qual a razão encontra bastante dificuldade em manter o equilíbrio entre a excitação que acaba e a depressão que começa, ainda que às vezes seja possível constatar os esforços do doente para consegui-lo.

O mais comum é que o estado de depressão estabeleça-se progressivamente, especialmente na forma circular de longos períodos; mas não negamos que em alguns casos excepcionais, a depressão assim como a excitação possam ser bruscas em sua aparição.

No começo do período de depressão, os doentes em vez de colocarem-se diante das pessoas para sobrecarregá-las com a volubilidade de suas palavras, em vez de importunar aqueles que os rodeiam, de fazer travessuras, e de entregarem-se à alegria, começam a manter-se à distância e proferem apenas raras palavras. Algumas vezes agem como uma pessoa que sentisse vergonha do estado precedente, do qual conservam uma lembrança mais ou menos completa. Há outros que ficam num estado de humildade. Em pouco tempo, todos esses sintomas aumentam; os doentes ficam então totalmente solitários e imóveis. Tanto 


\section{CLÁSSICO S DA \\ PSICOPATOLOGIA \\ ano $V$, n. 4, dez/ 2002}

quanto eram exigentes no período de excitação, são humildes no período de depressão, e sua humildade vai algumas vezes até a recusa dos cuidados que lhes são dispensados, acreditando não merecê-los.

O enfraquecimento torna-se dia-a-dia mais pronunciado; em certos casos, chega enfim o momento em que o doente fica como que transformado numa estátua. O próprio instinto de conservação está enfraquecido ao ponto do doente não ter a impulsão suficiente para ir buscar os alimentos ou para pedi-los se não lhe forem oferecidos, mesmo que seja insistentemente solicitado.

O curso das idéias fica muito lentificado; mas é raro entretanto, que esse estado chegue até a suspensão completa da inteligência, até o idiotismo acidental.

Os sentimentos ficam muito enfraquecidos: o doente não manifesta nem simpatia e nem antipatia; ele deixa-se levar sem reação pela impulsão que se lhe dá. Perdeu toda espontaneidade de ação. Os movimentos são lentos, nulos ou quase nulos. Freqüentemente se é obrigado a arrastá-los para onde se quer conduzi-los, a vesti-los, a desvesti-los, ou pelo menos a dar-lhes o impulso para que completem esses atos.

Os sintomas físicos são os seguintes: a face fica pálida; os traços, puxados para baixo, demonstram mais o enfraquecimento que a ansiedade. Os olhos são opacos, as pálpebras apenas entreabertas, e todos os sentidos parecem adormecidos. O doente parece experimentar um sentimento de mal-estar geral e todos os órgãos da locomoção ficam num estado de torpor. O apetite fica muito diminuído; o doente come lentamente; a digestão é igualmente lenta e a defecação se faz com dificuldade. O sono é melhor que durante o período de excitação, mas não é nem regular e nem prolongado.

São estes os fenômenos mais constantes no estado de depressão, o que nos fez dizer que tratava-se do fundo do estado melancólico, sem seus pontos de destaque, quer dizer, sem idéias delirantes bem determinadas. Porém, existem alguns doentes que apresentam idéias predominantes, e entre essas idéias destacaremos sobretudo as de humilhação, de ruína, de envenenamento e de culpabilidade.

O período de depressão geralmente é mais longo que o período de excitação; é comum que aquele tenha uma duração tanto maior quanto mais prolongada tenha sido a própria exaltação. Entretanto há casos, e principalmente acessos, em que os dois períodos parecem ter mais ou menos a mesma duração. O período de depressão, depois de ter chegado ao seu apogeu e aí permanecer estacionado, declina pouco a pouco e em geral passa por graduações insensíveis até o intervalo lúcido.

Progressivamente, o doente parece despertar para a vida de relação; sai do torpor físico e moral; fala com mais boa vontade e retorna a seus hábitos de ordem e de trabalho, ainda que com certa lentidão e sem efusão. Mas, na maioria 
dos casos, em breve o doente torna pouco a pouco a ser o que era no estado de saúde, com um certo rebaixamento de nível da inteligência. Está ainda no estado de depressão, embora para o observador inexperiente, já esteja no estado de razão. Com efeito, quanto mais se tiver sagacidade e experiência na apreciação desse grau de depressão que precede o retorno completo ao estado normal, mais parecerá diminuída a duração do intervalo lúcido; quanto mais difícil for proferir que o doente recuperou totalmente sua razão, mais a duração real do intervalo lúcido encontrar-se-á abreviada. Porém esse intervalo lúcido existe. Habitualmente é menos longo que os períodos de excitação e de depressão considerados isoladamente; mas sua duração é muito variável, principalmente de acordo com o fato da loucura circular ser de curtos ou de longos períodos. Efetivamente, nesse último caso, o intervalo lúcido pode ter uma longa duração.

As mesmas reflexões que nós fizemos sobre seu começo, aplicam-se a seu declínio. O observador sagaz já vê despontar a excitação enquanto que as pessoas inexperientes ainda acreditam numa razão completa. Os sintomas de invasão do período de excitação aparecem então, como havíamos indicado, e um novo círculo doentio começa, para desenvolver-se em seguida com as mesmas características e ter o mesmo final. A vida desse tipo de doente passa-se dessa maneira, como já dissemos, na reprodução contínua desse movimento circular.

A loucura circular encontra-se assim descrita em suas características gerais; pois não temos a pretensão de fazer mais do que esboçar sua descrição em traços gerais, que mereceria com toda razão um estudo mais aprofundado; mas pensamos ao menos ter dado uma idéia exata de seus principais sintomas.

Resta-nos agora extrair fatos e considerações que precedem algumas conseqüências práticas e que decorrem imediatamente do próprio conhecimento dessa forma. Primeiramente: é freqüente essa forma de doença mental? A julgar pela pouca atenção dispensada até aqui aos fatos desse gênero, e mesmo pelo número dos que encontram-se nos asilos, ela não seria freqüente; mas há várias causas de erro que impedem que se aprecie exatamente seu grau de freqüência. Efetivamente, em geral não se acompanha com suficiente cuidado o desenvolvimento das doenças mentais. O mais comum é que se contente em observar um doente num dado momento e não durante todo o curso de sua afecção. Resulta daí que, nessa direção da observação, faz-se constar esses doentes ora entre os maníacos, ora entre os melancólicos, segundo o momento em que os observamos. Por outro lado, é raro que o médico tenha condições suficientemente favoráveis para poder acompanhar o mesmo doente durante longos anos. Além do mais, como essa forma de doença mental, nos dois períodos que a constituem, em geral não apresenta o grau de intensidade da mania e da alienação parcial propriamente ditas, segue-se naturalmente que os doentes desse gênero permanecem muitas vezes na sociedade. Nós temos segurança disso 


\section{CLÁSSICO S DA \\ PSICOPATOLOGIA \\ ano $V$, n. 4, dez/ 2002}

pela observação direta, pois fomos consultados por alguns doentes que há muito tempo são acometidos dessa forma de doença mental e que jamais despertaram de maneira suficientemente profunda a solicitude de seus pais para que tenha tido a intenção determinada de isolá-los em estabelecimentos especiais. Tivemos ainda as mais freqüentes provas, interrogando os parentes de nossos doentes sobre os antecedentes de sua afecção e sobre as disposições dos ascendentes. Pudemos então discernir, apesar das variadas locuções que eles empregavam para mascarar tal estado, que freqüentemente os ascendentes haviam apresentado essa forma de doença mental. Os pais são de fato hábeis em criar ilusões sobre a questão da hereditariedade e a forma circular da loucura favorece bastante o erro deles a esse respeito. O período de depressão para eles é apenas um estado de abatimento da alma, um desencorajamento, um enfraquecimento que atribuem com complacência aos motivos mais levianos. Aliás, os pais encontram muita facilidade para dissimular o estado de seus doentes aos olhos de todos, pois as pessoas de suas relações não saberiam descobrir aí um estado de loucura. Além do mais, o alienado permanece isolado em sua casa, fala raramente, não se entrega a nenhuma atividade, e como conseqüência não dá aos olhos do público nenhum testemunho de doença mental.

No período de excitação, há novos motivos de ilusões para seus pais e para suas relações habituais. Em geral os doentes estão excitados como fica-se, ao menos num grande número de casos, em certo momento da embriaguez. E então exclama-se que eles estão em seus momentos de alegria; os pais extasiam-se mesmo com a vivacidade, com os recursos de seus espíritos, e o mundo faz eco a tal maneira de interpretar essa situação mental. Eles apresentam alterações de sentimentos e entregam-se a atos desordenados e prejudiciais. Pode-se dizer que por alguns momentos eles têm um mal caráter, que são bizarros, turbulentos, difíceis de conviver; porém sem persistir no fato de que qualifica-se de loucura um tal estado.

As considerações que acabamos de apresentar sobre as informações fornecidas pelos pais, e ao mesmo tempo pela nossa experiência direta, nos fazem pensar que a loucura circular é bastante hereditária; todavia não podemos afirmar com certeza que ela o seja mais do que outras espécies de doença mental, embora nos inclinemos a pensá-lo. Primeiramente, todas as pesquisas sobre a hereditariedade da loucura são extremamente difíceis; em seguida, a observação não foi dirigida para a hereditariedade em suas relações com as diversas formas de doenças mentais; limitamo-nos a estudar a questão do ponto de vista da loucura em geral, ou ainda da mania e da melancolia que, segundo pensamos, não são verdadeiras formas naturais e reúnem estados muitos diferentes sob um mesmo nome. No que se refere à classificação das doenças mentais, estamos ainda na época dos Tournefort e dos Linné, e esperamos um Jussieu! 
A loucura circular, seja de curtos, seja de longos períodos, é infinitamente mais freqüente na mulher do que no homem. Nós tivemos a prova disso em nossa prática particular, fazendo anotações em nosso estabelecimento de Vanves e nos esclarecendo com nosso colega e amigo, o doutor Voisin que, testemunha de nossa observação sobre a loucura circular, fixou sua atenção há muito tempo nessa forma de doença mental em seu serviço de Bicêtre. Assim pudemos avaliar, comparativamente com meu serviço da Salpêtrière, que a loucura circular era muito mais freqüente na mulher que no homem, sem poder porém definir uma cifra exata a esse respeito. Todavia, em nosso estabelecimento, entre quatro doentes atingidos nesse momento, existem três mulheres e apenas um homem.

O prognóstico a ser estabelecido sobre essa forma de doença é muito grave. Não se pode absolutamente esperar mais do que melhoras no grau de intensidade dos acessos e um prolongamento na duração dos intervalos lúcidos, em geral tão curtos. Essa gravidade do prognóstico que infelizmente resulta de uma observação multiplicada, é tanto mais importante a ser apontada que ela não teria podido ser pressentida a priori, pois a loucura circular é constituída pela reunião de dois estados doentios que, tomados isoladamente, são susceptíveis de cura. Esse prognóstico parece desesperador, mas o conhecimento dessa gravidade tem várias vantagens. Por um lado, ele pode ser útil aos próprios doentes acometidos de loucura circular, provocando o cuidado dos práticos e lhes inspirando a perseverança necessária para variar as medicações contra uma afecção que pode bem ser incurável apenas no estado atual da ciência. Por outro lado, a distinção dessa forma de doença mental do deplorável prognóstico que se é obrigado a colocar a respeito de seu desfecho na época atual, impede de fazê-la entrar numa relação com outros estados mórbidos da inteligência. Isto é, por esse desfalque de uma forma de loucura incurável, outras espécies de doenças mentais são destacadas de um mau elemento, e seu prognóstico encontra-se tanto mais favorável.

Aliás, a determinação da forma circular, como de qualquer outra forma natural, será fecunda de bons resultados.

Entrar nessa nova via de classificação; basear as distinções das doenças mentais num conjunto de características subordinadas umas às outras e sobre seu desenvolvimento, quer dizer, sobre a evolução desses fenômenos sucedendose numa ordem determinada, é seguir um dos princípios que melhor podem levar a uma classificação regular, a um prognóstico esclarecido e a um tratamento racional. À medida que nos contentarmos com estudos sobre a loucura em geral e mesmo sobre a mania e a melancolia, tal como são descritas atualmente, será bem possível recolher documentos preciosos, mas certamente as conseqüências que se tirará das observações assim feitas não terão uma grande utilidade para a 
ciência, nem para a prática, porque serão deduzidas de fatos complexos, em vez de serem baseadas em fatos similares e bem determinados.

Essas notas sobre a necessidade de se estabelecer distinções entre as doenças mentais, verdadeiras do ponto de vista da classificação e do prognóstico, são ainda mais necessárias se relacionadas à terapêutica. Com efeito, de que modo instituir um tratamento e dar-se conta da forma de ação dos meios empregados, se previamente não se estabeleceu distinções rigorosas entre os fatos das doenças mentais? Como dar-se conta da ação dos meios terapêuticos se não se opera sobre fatos similares, ou pelo menos análogos, e se não se conhece de antemão a evolução natural da doença? É no entanto nessa deplorável direção que será instituído o tratamento enquanto que os agentes curativos serão unicamente dirigidos contra a loucura em geral, e mesmo contra a mania e a melancolia, já que sob essas denominações encontram-se incluídos estados doentios que necessitam ser cuidadosamente diferenciados.

Enfim, a constatação da loucura circular será igualmente útil em certos casos de medicina legal relacionada aos alienados. Se os doentes atingidos por essa forma de loucura, que permanecem em suas famílias e na sociedade, se entregarem a atos nocivos da alçada de tribunais, o médico que conhecer as características e a evolução dessa afecção encontrará nesse conhecimento um apoio bastante precioso para esclarecer os magistrados. Qualquer que seja o momento em que for solicitado, ele poderá demonstrar todas as fases da doença diante dos juizes, com a certeza de que o que apresenta poderá ser verificado por todos, sobretudo na forma circular de curtos intervalos. Se o médico perito for chamado durante o intervalo lúcido, seu conhecimento sobre o andamento da loucura circular o fará responder com segurança que a doença irá apresentarse novamente com suas duas fases, e o fato justificará seu prognóstico. A medicina legal se apoiará então sobre o estudo clínico da evolução natural da doença, em vez de basear-se sobre a apreciação individual dos caracteres e dos motivos do ato incriminado, ou sobre a observação médica limitada a um dado momento. O médico perito poderá assim fornecer todos os esclarecimentos para que se faça justiça, seja por tratar-se de um seqüestro considerado ilegal, seja por ele ter que pronunciar-se sobre o valor de um testamento, sobre a necessidade de uma interdição, ou sobre um ato que seria criminoso se não tivesse como desculpa a alienação mental. 